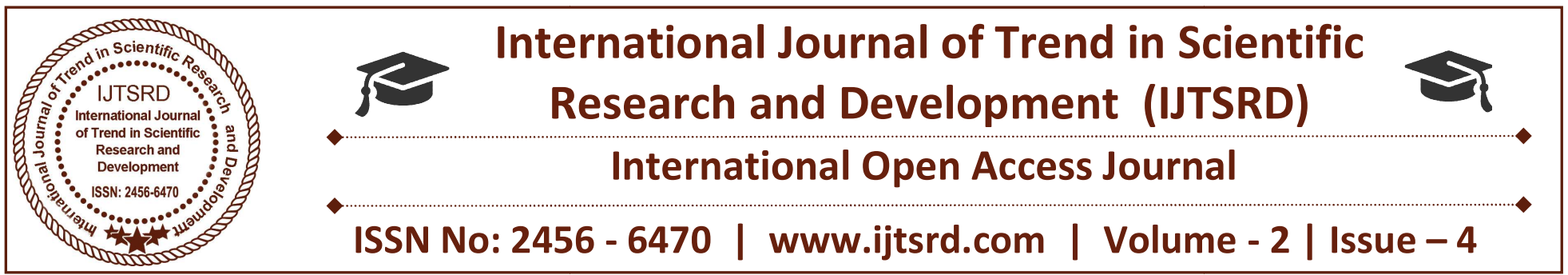

\title{
Prediction of safe working frequencies of screening machine by Harmonic Analysis
}

\author{
Hajare Prashantbhai A \\ Assistant Professor, Vadodara Institute of Engineering, \\ Kotambi, Vadodara, Gujarat India
}

\section{ABSTRACT}

The vibratory screening machine is used in different industries like mining, pharmaceutical, food etc. In the past, the study of screening machine has been done on the basis of its design parameters like diameter of wire, length, mesh size, throwing index etc. The work regarding vibration parameters is not widely done in the past. A little work on mathematical modeling has been done on the rectangular type vibratory screening machine. In this paper modal and harmonic analysis has been done to predict the natural frequencies of different mode shapes of the circular vibratory screening machine. This analysis can be used as the methodology for the further study of the VSM. In this dissertation work it the design and working frequencies of the screening machine are of safe region.

Keywords: Modal Analysis, Harmonic Analysis, Natural frequencies of Vibrating screening Machine

\section{INTRODUCTION}

Industrial screens are used in the minerals processing industry to separate solids from liquids and to separate particulate materials into different size ranges. Screening has been extensively used since the Greeks used horse hair-and-reed sieves to effect particle size separation. The first woven wire screens dates back to the 15th century Germany and remain largely unchanged today. Sieves and screens are used

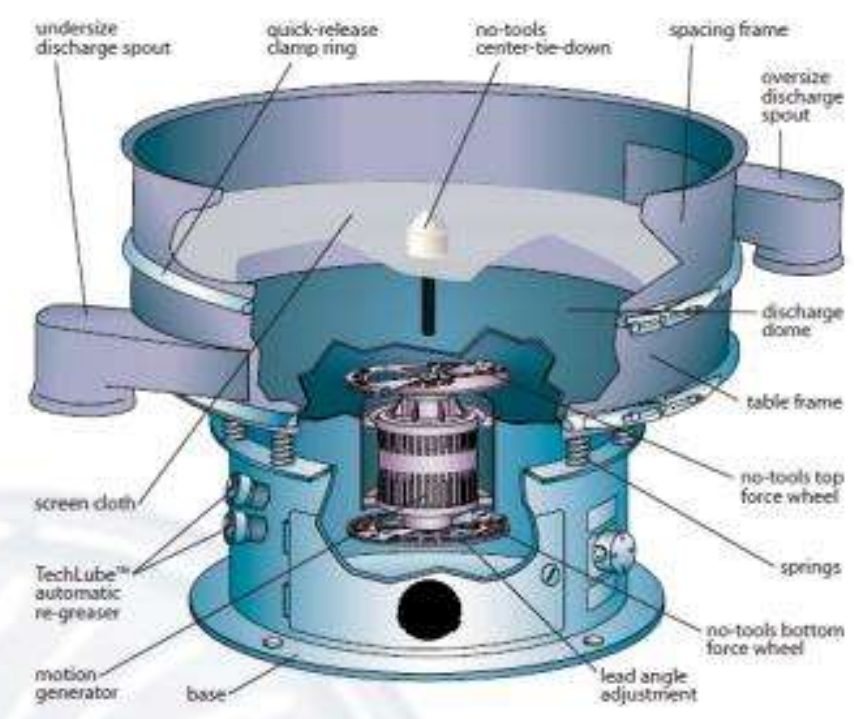

Figure 1: Vibratory Screening Machine

both industrially and in the laboratory to classify particulate material by particle size. The term "screening" is commonly used to mean a continuous sizing operation as distinct from sieving, which is a

batch operation. The principles of size separation during screening and sieving are the same. Even in these early times, it was realized that shaking the screen by hand the efficiency of the screening process is improved.

Basically, the vibrating screening machine vibrates about its centre of mass. Vibration is accomplished by eccentric weights on the upper and lower ends of the motion-generator shaft. Rotation of the top weight creates vibration in the horizontal plane, which causes 
material to move across the screen cloth to the periphery. This is the reason why conventional systems cannot be used with slightly sticky and/or agglomerating materials, with heavy meshes (over 300 microns) or with large machines, especially rectangular screeners. On the contrary, the energy output capabilities of the Vibratory Screening Machine are so huge, that practically all kinds of materials are de-agglomerated and clogging of the mesh by any powder or slurry is avoided. Therefore the Vibratory Screening Machine can easily work with all meshes from 15 microns to $30 \mathrm{~mm}$

\section{MODAL ANALYSIS}

\section{A Model of Vibrating Screening Machine using}

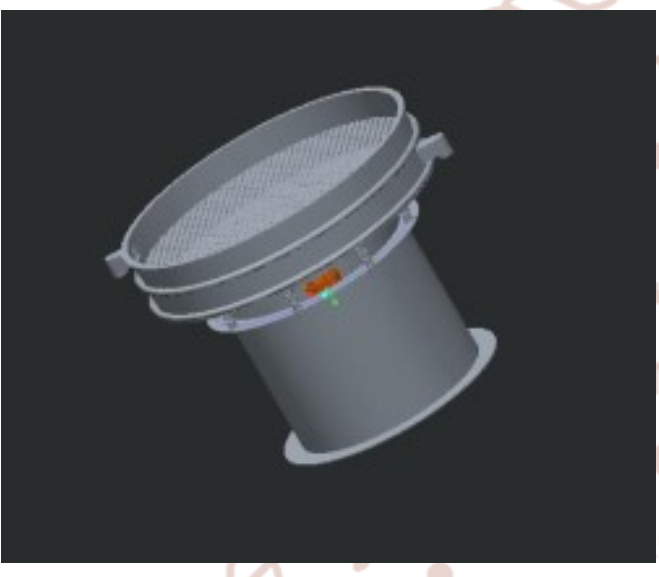

Figure 2: Vibrating screening machine using creo 2.0

Modal Analysis of vibrating Screening Machine:

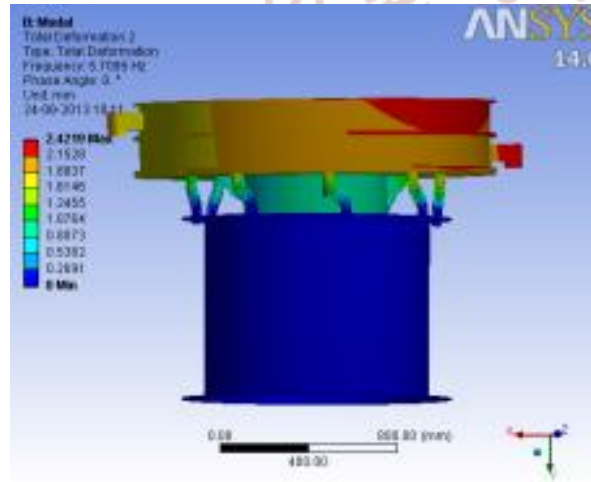

Figure 3: Mode shape of $2^{\text {nd }}$ Mode frequency

Fig shows the initial motion for second mode of frequency which indicating horizontal and vertical motions of screen. By observing the figure we can conclude that the maximum deformation generated on the frequency of $5.7095 \mathrm{~Hz}$.

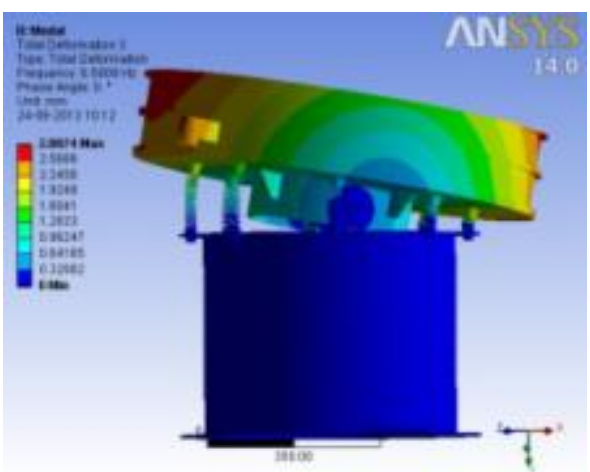

Figure 4: Mode shape of $4{ }^{\text {nd }}$ Mode frequency

In Figure, we can clearly observe all three motions of VSM. For the third mode of frequency the maximum deformation or the maximum amplitude is observed at the frequency of $6.5909 \mathrm{~Hz}$.

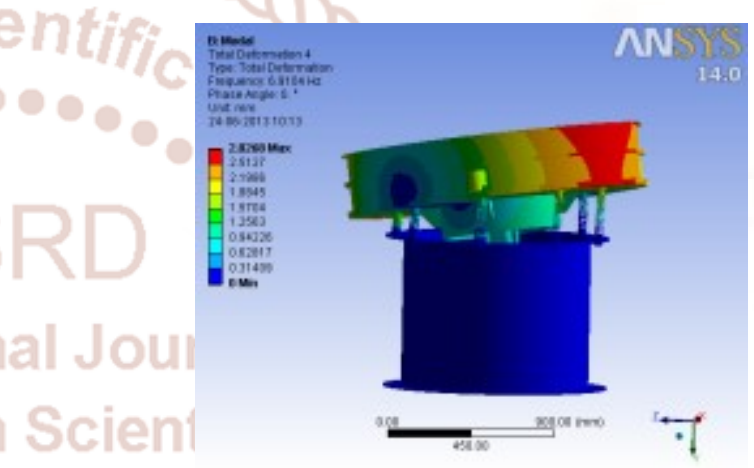

Figure 5: Mode shape of $4^{\text {nd }}$ Mode frequency

In figure the maximum amplitude is at the frequency of $6.9104 \mathrm{~Hz}$. The Modal analysis is done for finding the natural frequencies of the VSM. In this analysis we have considered six natural frequencies for finding its mode shapes and to observe and analyze the different motions of VSM.

As the result of Modal analysis the six natural frequencies for six modes of vibrating screening machine are listed in the table given below. The frequency for first mode is $2.0308 \mathrm{~Hz}$ and that for the sixth mode is $48.412 \mathrm{~Hz}$.

The all six natural frequency for six modes of VSM

\begin{tabular}{|l|l|}
\hline Mode & Frequency [Hz] \\
\hline 1 & 2.0308 \\
\hline 2 & 5.7095 \\
\hline 3 & 6.5909 \\
\hline 4 & 6.9104 \\
\hline 5 & 46.843 \\
\hline 6 & 48.412 \\
\hline
\end{tabular}


International Journal of Trend in Scientific Research and Development (IJTSRD) ISSN: 2456-6470

\section{HARMONIC ANALYISIS}

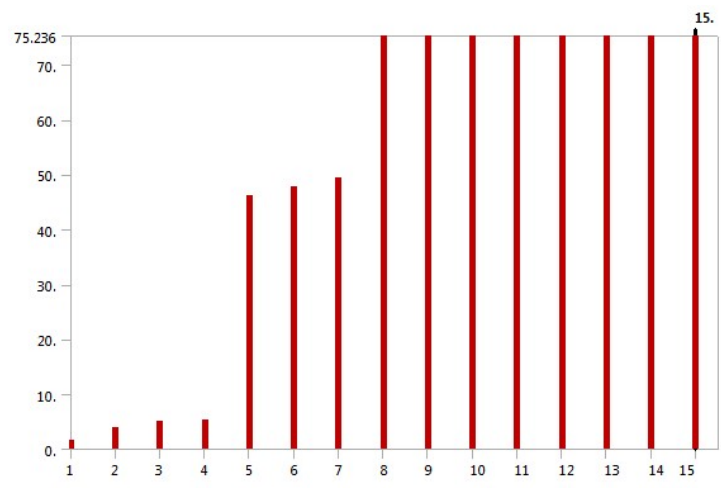

Figure 6: Modes v/s Frequency by harmonic analysis for the actual frequency range

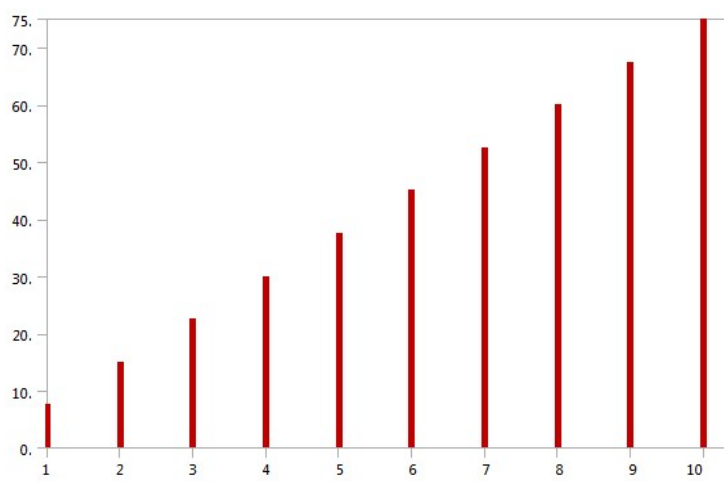

Figure 7: Modes v/s Frequency by harmonic analysis for the preferred frequency range

Frequencies of actual harmonic analysis and of preferred range:

\begin{tabular}{|l|l|l|}
\hline Mode & $\begin{array}{l}\text { Actual } \\
\text { Frequency } \\
{[\text { Hz] }}\end{array}$ & $\begin{array}{l}\text { Preferred } \\
\text { Frequency } \\
{[\text { Hz] }}\end{array}$ \\
\hline 1. & 1.6542 & 7.5 \\
\hline 2. & 3.9896 & 15 \\
\hline 3. & 5.0903 & 22.5 \\
\hline 4. & 5.3485 & 30 \\
\hline 5. & 46.194 & 37.5 \\
\hline 6. & 47.743 & 45 \\
\hline 7. & 49.367 & 52.5 \\
\hline 8. & 75.191 & 60 \\
\hline 9. & 75.195 & 67.5 \\
\hline 10. & 75.198 & 75 \\
\hline 11. & 75.213 & 75 \\
\hline 12. & 75.216 & 75 \\
\hline 13. & 75.221 & 75 \\
\hline 14. & 75.224 & 75 \\
\hline 15. & 75.236 & 75 \\
\hline & & \\
\hline
\end{tabular}

\section{RESULTS}

\begin{tabular}{|l|l|l|l|}
\hline & & \multicolumn{2}{|l|}{ Deformation Y Direction } \\
\hline $\begin{array}{l}\text { Sr. } \\
\text { No. }\end{array}$ & $\begin{array}{l}\text { Frequency } \\
{[\mathrm{Hz}]}\end{array}$ & $\begin{array}{l}\text { Amplitude } \\
{[\mathrm{mm}]}\end{array}$ & $\begin{array}{l}\text { Amplitude } \\
{[\mathrm{mm}]}\end{array}$ \\
\hline 1 & 7.5 & 0.13074 & 0.13074 \\
\hline 2 & 15 & 0.14105 & 0.14105 \\
\hline 3 & 22.5 & 0.16166 & 0.16166 \\
\hline 4 & 30 & 0.20315 & 0.20315 \\
\hline 5 & 37.5 & 0.30315 & 0.30315 \\
\hline 6 & 45 & 0.76449 & 0.76449 \\
\hline
\end{tabular}

\begin{tabular}{|l|l|l|l|}
\hline & & \multicolumn{2}{|l|}{ Deformation X Direction } \\
\hline $\begin{array}{l}\text { Sr. } \\
\text { No. }\end{array}$ & $\begin{array}{l}\text { Frequency } \\
{[\mathrm{Hz}]}\end{array}$ & $\begin{array}{l}\text { Amplitude } \\
{[\mathrm{mm}]}\end{array}$ & $\begin{array}{l}\text { Amplitude } \\
{[\mathrm{mm}]}\end{array}$ \\
\hline 1 & 7.5 & $1.10 \mathrm{E}-03$ & $1.10 \mathrm{E}-03$ \\
\hline 2 & 15 & $4.74 \mathrm{E}-05$ & $4.74 \mathrm{E}-05$ \\
\hline 3 & 22.5 & $2.56 \mathrm{E}-04$ & $2.56 \mathrm{E}-04$ \\
\hline 4 & 30 & $5.12 \mathrm{E}-04$ & $5.12 \mathrm{E}-04$ \\
\hline 5 & 37.5 & $1.31 \mathrm{E}-03$ & $1.31 \mathrm{E}-03$ \\
\hline 6 & 45 & $1.14 \mathrm{E}-02$ & $1.14 \mathrm{E}-02$ \\
\hline
\end{tabular}

\begin{tabular}{|l|l|l|l|}
\hline & & \multicolumn{2}{|l|}{ Deformation Z Direction } \\
\hline $\begin{array}{l}\text { Sr.64 } \\
\text { No. }\end{array}$ & $\begin{array}{l}\text { Frequency } \\
{[\mathrm{Hz}]}\end{array}$ & $\begin{array}{l}\text { Amplitude } \\
{[\mathrm{mm}]}\end{array}$ & $\begin{array}{l}\text { Amplitude } \\
{[\mathrm{mm}]}\end{array}$ \\
\hline 1 & 7.5 & $1.62 \mathrm{E}-04$ & $1.62 \mathrm{E}-04$ \\
\hline 2 & 15 & $4.10 \mathrm{E}-04$ & $4.10 \mathrm{E}-04$ \\
\hline 3 & 22.5 & $6.17 \mathrm{E}-04$ & $6.17 \mathrm{E}-04$ \\
\hline 4 & 30 & $1.02 \mathrm{E}-03$ & $1.02 \mathrm{E}-03$ \\
\hline 5 & 37.5 & $2.48 \mathrm{E}-03$ & $2.48 \mathrm{E}-03$ \\
\hline 6 & 45 & $3.89 \mathrm{E}-02$ & $3.89 \mathrm{E}-02$ \\
\hline
\end{tabular}

\section{CONCLUSIONS}

By the Harmonic Analysis done on Vibrating Screening machine, it is observed that the maximum amplitudes of deformation in $\mathrm{X}, \mathrm{Y}$ and $\mathrm{Z}$ directions are $0.011442,0.97638$ and $0.038935 \mathrm{~mm}$ respectively. And these amplitudes are at safe frequency range for the optimal screening process.

The frequency range for these amplitudes is $45 \mathrm{~Hz}$ to $52.5 \mathrm{~Hz}$. This frequency range is the safe working range for the VSM. 
International Journal of Trend in Scientific Research and Development (IJTSRD) ISSN: 2456-6470

\section{REFERENCES:}

1. W. Vorster, A. Hinde, F. Schiefer. "Increased screening efficiency using a Kroosher unit coupled with a Sweco screen (Part 1)" Minerals Engineering 15 (2002) pp 107-110

2. Song Yan, Jiang Xiao-hong, Song Juan, Zhang Jian-xun "Dynamic analysis of a chaotic vibrating screen" Procedia Earth and Planetary Science 1 (2009) pp 1525-1531

3. HE Xiao-mei, LIU Chu-sheng "Dynamics and screening characteristics of a vibrating screen with variable elliptical trace" Mining Science and Technology 19 (2009) pp 0508-0513

4. [4] LIU Chu-sheng, ZHANG Shi-min et al "Dynamic analysis and simulation of four-axis forced synchronizing banana vibrating screen of variable linear trajectory" J. Cent. South Univ. 19 (2012) pp 1530-1536

5. [5] CHEN Yan-hua, TONG Xin "Application of the DEM to screening process: a 3D simulation"
Mining Science and Technology 19 (2009) pp 0493-0497

6. [6] CHEN Yan-hua, TONG Xin "Modeling screening efficiency with vibrational parameters based on DEM 3D simulation" Mining Science and Technology 20 (2010) pp 0615-0620

7. [7] Wang Guifeng, Tong Xin "Screening efficiency and screen length of a linear vibrating screen using DEM 3D simulation" Mining Science and Technology (China) 21 (2011) pp 451-455

8. [8] Xiao Jianzhang, Tong Xin "Particle stratification and penetration of a linear vibrating screen by the discrete element method" International Journal of Mining Science and Technology 22 (2012) pp 357-362.

9. [9] Prashant Hajare, "A Review on mathematical modeling and simulation of Exciter of Vibrating Screening machine" National conference in Recent Research and Development in Core Disciplines in Engineering (2015).

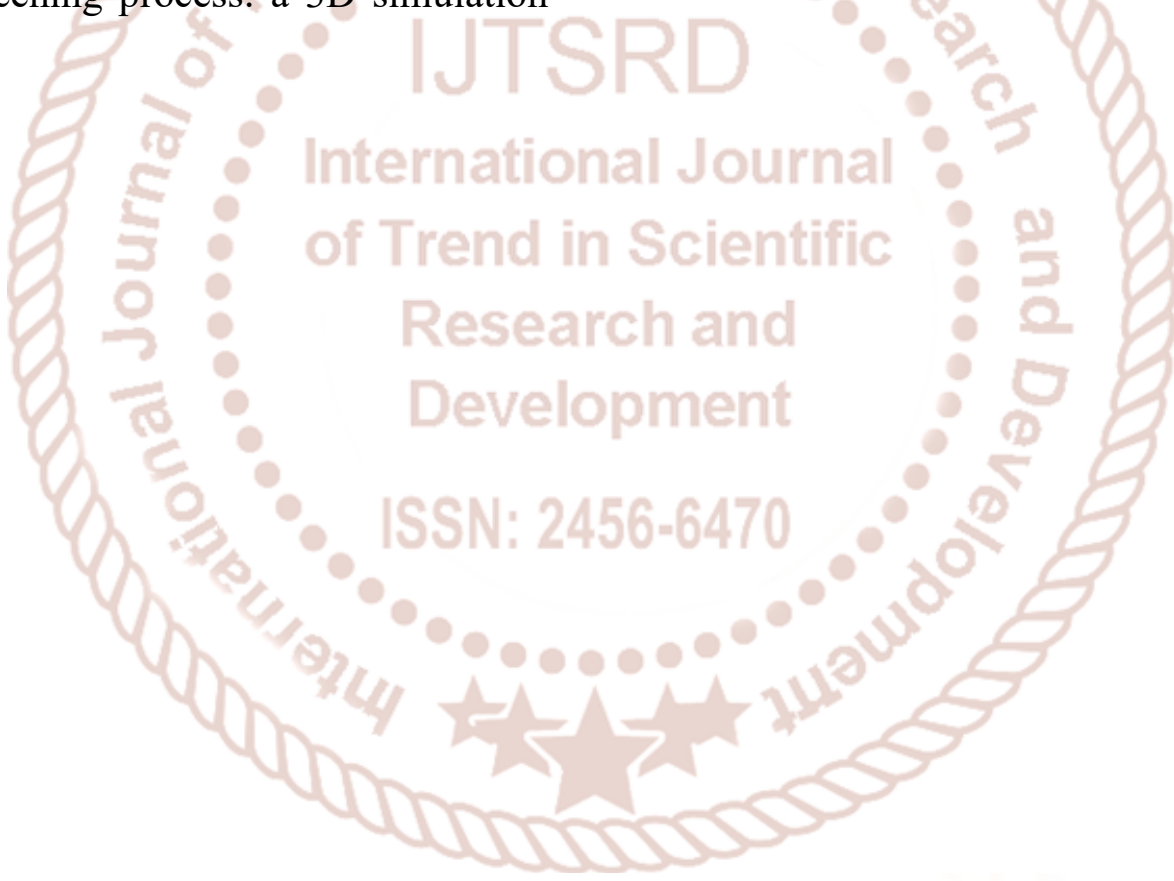

